\title{
Simultaneous multi-colony tracking of a pelagic seabird reveals cross-colony utilization of a shared foraging area
}

\author{
Ben Dean ${ }^{1}$, Holly Kirk ${ }^{1}$, Annette Fayet ${ }^{1}$, Akiko Shoji ${ }^{1}$, Robin Freeman ${ }^{2}$, \\ Kerry Leonard ${ }^{3}$, Christopher M. Perrins ${ }^{4}$, Tim Guilford ${ }^{1, *}$ \\ ${ }^{1}$ Animal Behaviour Research Group, Department of Zoology, South Parks Road, Oxford, OX1 3PS, UK \\ ${ }^{2}$ Institute of Zoology, Zoological Society of London, Regents Park, NW2 4RY, UK \\ ${ }^{3}$ Copeland Bird Observatory, C/O Birch Park, Bangor, County Down, Northern Ireland, BT19 1RZ, UK \\ ${ }^{4}$ Edward Grey Institute of Field Ornithology, Department of Zoology, South Parks Road, Oxford, OX1 3PS, UK
}

\begin{abstract}
The role that population-level competition plays in regulating foraging distributions of colonial breeders has remained elusive because many studies of animal movements in the natural environment focus on relatively small datasets from a single population of animals. Here, we present a large (528 foraging trips, 169 individuals), multi-year, multi-colony GPS tracking dataset mostly collected simultaneously at 4 breeding colonies across the core breeding range of a colonially breeding pelagic seabird, the Manx shearwater Puffinus puffinus. Foraging areas were identified by filtering GPS locations (using speed, time of day, and turning angle), validated on a subset of 25 birds carrying co-deployed depth loggers to maximise inclusion of foraging and feeding behaviour. Foraging areas showed high annual variation, but consistent patterns emerged. Birds from each colony consistently foraged locally, showing little overlap between colonies, but birds from all 4 colonies sometimes travelled large distances to forage within a single relatively restricted area. This combined pattern may be driven by density-dependent competition relatively locally, with high overlap and resource sharing at a distance, facilitated by a dual foraging strategy of mixing short and long trips. The key shared area was located near to a tidal front system, the Irish Sea Front, and the stratified waters of the Western Irish Sea to its north and west, which are characterised by high productivity. Visits to this area declined with increasing colony distance, suggesting that foraging advantages are balanced by the energetic costs of travel. Nevertheless, this area is probably of key importance to birds breeding at colonies across the species' core breeding range, highlighting the potential connectedness, and therefore vulnerability, of a pelagic species via a single foraging location, despite apparent segregation more locally around the breeding colonies.
\end{abstract}

KEY WORDS: Density-dependent competition · Colony segregation · Foraging $\cdot$ Resource sharing · Multi-colony tracking $\cdot$ Pelagic seabird $\cdot$ Manx shearwater

\section{INTRODUCTION}

Seabirds are long-lived, widespread, upper-trophic marine organisms with high adult survival and slow population growth (Ricklefs 1990). Many are colonial breeders, yet highly pelagic foragers, so fundamental ecological processes such as density-dependent competitive segregation and the economics of central

${ }^{*}$ Corresponding author: tim.guilford@zoo.ox.ac.uk place foraging may be important in shaping their distributions and behaviour at sea (Ashmole 1963, Cairns 1989, Furness \& Birkhead 1984, Wakefield et al. 2013). Nevertheless, release from competition because of summer resource abundance could instead facilitate inter-colony sharing of foraging areas in temperate breeding species (Furness \& Birkhead 1984). Seabirds' life-styles also make them poten-

(C) The authors 2015. Open Access under Creative Commons by Attribution Licence. Use, distribution and reproduction are unrestricted. Authors and original publication must be credited. 
tially vulnerable to a wide range of impacts at sea, including pollution, incidental mortality in fisheries, incidental mortality and habitat loss associated with marine developments and changes in prey resources as a result of changes in fishery management, oceanic conditions and climate change (GonzálezSolís \& Shaffer 2009). Seabirds therefore function as important indicators of ocean health (Einoder 2009, Lewison et al. 2012), particularly in the light of global climate change (Grémillet \& Boulinier 2009) and our increasing use of the seas at industrial scales (Halpern et al. 2008).

Detailed knowledge of the patterns of movement and behaviour of seabirds at sea is therefore of both fundamental and applied value. Recent developments in miniature tracking technologies have further advanced the study of seabird spatial ecology by facilitating remote at-sea observation of individuals of known status and provenance (Phillips et al. 2007, Burger \& Shaffer 2008, Rutz \& Hays 2009, Bograd et al. 2010, Wilson \& Vandenabeele 2012). In particular, GPS and satellite tracking have provided a wealth of information about the foraging movements of individual birds during breeding (e.g. Grémillet et al. 2004, Pinaud \& Weimerskirch 2007, Weimerskirch et al. 2007, Guilford et al. 2008, Magalhães et al. 2008, Hamer et al. 2009, Paiva et al. 2010, Wakefield et al. 2011, 2013).

Nevertheless, a detailed understanding of the patterns and processes that shape seabird distributions and behaviour at sea can be obscured by the noisiness of both spatial and temporal snapshots in tracking studies, which are sensitive to variability from a range of factors such as changing prey distributions (Fauchald 2009), weather (Finney et al. 1999, Garthe et al. 2009), oceanic features (Durazo et al. 1998, Garthe et al. 2009) or moon phase (Riou \& Hamer 2008, Yamamoto et al. 2008, Guilford et al. 2012). Much more information is needed as to how animals of known status from different colonies respond concurrently, and across multiple seasons (Ramos et al. 2013, Wakefield et al. 2013).

The aim of this study was to understand the spatial patterns of multi-colony resource use in a colonially breeding pelagic seabird, using an ethoinformatics approach (Dean et al. 2012, Freeman et al. 2013) to identify the foraging activity of known individuals remotely. Specifically, we aimed to (1) map the foraging distributions of birds tracked from several colonies across a species' core breeding range during the same period, (2) assess the extent to which birds from different colonies either segregated or foraged in the same locations at the same time and (3) assess the consistency of those patterns across years. We studied the $400 \mathrm{~g}$ Manx shearwater Puffinus puffinus, a pelagic central-place forager, predominantly of small clupeids, which does not show interactions with fishing vessels or exploit discards. Manx shearwaters engage in long-distance foraging movements, over both inshore waters and open sea (Brooke 1990, Gray \& Hamer 2001, Guilford et al. 2008, Dean et al. 2012, Freeman et al. 2013), but observations of foraging distributions have so far been largely limited to at-sea counts of birds of unknown provenance (Stone et al. 1994). Whilst this species is IUCN Least Concern, the majority of breeding is restricted to a small number of colonies around the UK and Ireland, with little known about colonies' patterns of at-sea resource use. We used miniature GPS loggers to record simultaneously the foraging trips of a large number of birds from multiple colonies over 3 consecutive years. We tracked birds from 2 colonies (Copeland and Skomer) simultaneously during the incubation period and from up to 4 colonies (Rum, Copeland, Skomer and Lundy) largely simultaneously during the chick-rearing period. We identified likely foraging locations by filtering tracks using the times of day, movement speeds and turning angles that optimized inclusion of actual diving behaviour in a sub-set of 25 individuals that were also equipped with miniature depth loggers. We mapped concurrent foraging distributions from each colony, period and year to determine the extent of spatial overlap and thus the potential influence of competitive segregation or resource sharing.

\section{MATERIALS AND METHODS}

\section{Data loggers}

Logger deployments were made over 3 consecutive years on birds breeding at 4 colonies across the species' core breeding range (see Fig. S1 in the Supplement at www.int-res.com/articles/suppl/m538 p239_supp.pdf; Mitchell et al. 2004). During incubation (May-June 2009-2011), loggers were deployed on birds from Lighthouse Island in the Copelands group, Northern Ireland $\left(54^{\circ} 41^{\prime} \mathrm{N}, 5^{\circ} 31^{\prime} \mathrm{W}\right)$, and Skomer Island, Wales $\left(51^{\circ} 44^{\prime} \mathrm{N}, 5^{\circ} 17^{\prime} \mathrm{W}\right)$. During chick-rearing (July-August 2009-2011), loggers were deployed on birds from Copeland, Skomer and Lundy Island, England (51 $\left.10^{\circ} \mathrm{N}, 4^{\circ} 40^{\prime} \mathrm{W}\right)$. During chick-rearing 2010 and 2011, loggers were also deployed on birds from the Isle of Rum, Scotland $\left(56^{\circ} 59^{\prime} \mathrm{N}, 6^{\circ} 17^{\prime} \mathrm{W}\right)$. As far as practicable, deployments were carried out simultaneously on different 
islands (Fig. S1 in the Supplement), although in 2010 deployments on Lundy were started $22 \mathrm{~d}$ earlier than the other colonies for logistically unavoidable reasons. Overall, 264 deployments were made on 173 individuals (Table 1). Breeding adults were taken from their burrows by hand through a purpose-built inspection hatch, or using a purse net at the burrow entrance (Lundy only), weighed using a spring balance and fitted with devices (max. 15 min handling time). Birds were recaptured 3 to $12 \mathrm{~d}$ later after returning from their foraging trip, reweighed after being allowed to feed their chick, had the devices removed (max. $10 \mathrm{~min}$ ), and then were returned to their burrow. For nests on Skomer in 2009 and 2011, chicks were also weighed daily using an electronic scale.

All birds were fitted with a global positioning system (GPS) logger (modified i-gotU GT-120: Mobile Action), configured to record location every 5 or $10 \mathrm{~min}$, sealed in heat-shrink plastic and attached dorsally using thin strips of tesa ${ }^{\circledR}$ marine cloth tape (Beiersdorf) underlying a small number of contour feathers (Guilford et al. 2008, Dean et al. 2012). Birds also carried a British Antarctic Survey geolocatorimmersion logger (GLS; data not used here) attached by cable ties to a plastic leg ring. Twenty-five birds tracked from Skomer (Table 1) were additionally fitted with a CEFAS G5 time-depth recorder (TDR), recording pressure every $1 \mathrm{~s}$, attached to the central 4 tail feathers using thin strips of tesa tape (Dean et al. 2012). The GPS logger weighed 10.2 to $15 \mathrm{~g}$ (small batteries were used for birds carrying TDRs), the GLS logger weighed $1.4 \mathrm{~g}$ to $2.5 \mathrm{~g}$, and TDRs weighed $2.7 \mathrm{~g}$. The total mass of devices and attachments (18 to $19.5 \mathrm{~g}$ ) comprised approximately $4.5-5.2 \%$ and $4.3-5.0 \%$ of deployment body mass during incubation and chick-rearing, respectively. When birds were recaptured and devices had been deployed $<1 \mathrm{wk}$ and were still well attached, the bird was released; otherwise, the devices were removed. The effects of tracking on breeding success were tested for birds tracked from Skomer in 2009 and 2011 by comparison of hatching success, chickgrowth and fledging success with control nests where no tracking was carried out.

\section{Foraging movements}

For each complete tracked foraging trip within the bounds of the continental shelf waters $(94 \%$; see 'Results'), we calculated the total track length, the total trip duration and the daily distance travelled. Maximum distance from the colony was calculated for all these complete trips and for those in which the GPS device stopped recording after the bird was deemed to have started its return to the colony (all but 5 trips). For each colony and period, the relationship between foraging trip maximum distance and duration was tested using generalized linear mixed models with duration as the dependent variable, maximum distance as a fixed effect, and individual bird as a random effect. Long- and short-distance trips were delineated by a $200 \mathrm{~km}$ maximum distance contour, a distance giving good separation between chick-provisioning and self-maintenance trips in this species (Shoji et al. 2015) and similar to that used to define local foraging in the related Cory's shearwater (Ceia et al. 2015). An additional 6 very long-range trips into the Atlantic beyond the continental shelf edge (see Fig. S5 in the Supplement) were excluded from all analyses as outliers because they probably represent a different kind of rare foraging event.

Behavioural resolution of seabird GPS tracks can be improved by filtering locations likely to indicate foraging (as opposed to commuting flight or resting, for example) by using movement parameters such as

Table 1. The number of birds tracked and trips recorded with GPS from each colony during each period (incubation, chickrearing) of each year. Birds from Skomer for which we obtained diving data are shown in square brackets. Approximate colony sizes (breeding pairs) are also given

\begin{tabular}{|c|c|c|c|c|c|c|c|}
\hline & & \multicolumn{2}{|c|}{$2009-$} & \multicolumn{2}{|c|}{$-2010 \square$} & \multicolumn{2}{|c|}{$2011 \longleftarrow$} \\
\hline & & Incubation & Chick-rearing & Incubation & Chick-rearing & Incubation & Chick-rearing \\
\hline \multirow[t]{2}{*}{ Rum (120 000 pairs) } & $\mathrm{N}$ birds & - & - & - & 9 & - & 15 \\
\hline & $\mathrm{N}$ trips & - & - & - & 20 & - & 58 \\
\hline \multirow[t]{2}{*}{ Copeland (4600 pairs) } & $\mathrm{N}$ birds & 15 & 20 & 11 & 20 & 15 & 22 \\
\hline & $\mathrm{N}$ trips & 16 & 48 & 11 & 26 & 19 & 87 \\
\hline \multirow[t]{2}{*}{ Skomer (316 000 pairs) } & $\mathrm{N}$ birds & 9 & $18[16]$ & 8 & $26[9]$ & 13 & 18 \\
\hline & $\mathrm{N}$ trips & 9 & $24[20]$ & 8 & $69[14]$ & 13 & 47 \\
\hline \multirow[t]{2}{*}{ Lundy (1100 pairs) } & $\mathrm{N}$ birds & - & 10 & - & 11 & - & 14 \\
\hline & $\mathrm{N}$ trips & - & 15 & - & 29 & - & 29 \\
\hline
\end{tabular}


speed and tortuosity (Votier et al. 2010); by excluding times, such as night, when foraging is unlikely (Votier et al. 2010); and by using additional data from co-deployed devices such as immersion loggers (Granadeiro et al. 2011, Torres et al. 2013), dive loggers (Shoji et al. 2015), or both (Dean et al. 2012). Here, we adopted a 3 -stage filtering process including validation using an enriched subsample of 25 birds with corresponding diving data. Briefly (details in the Supplement at www.int-res.com/articles/suppl/ m538p239_supp.pdf), we excluded nocturnal locations (21:00 to 04:00 h GMT), high-speed movements (speeds $>7 \mathrm{~m} \mathrm{~s}^{-1}$ ) likely to be commuting flight, and movements with low variation in turning angle (standard deviation in turning angle $<18^{\circ}$ over a moving window of 6 sequential locations) likely to be resting and drifting on the surface. Thus, for the subset of birds with diving data, filtering excluded $50 \%$ of GPS locations but retained locations corresponding to $90 \%$ of all time spent submerged. Effectively validated by diving data, filtering was then applied to the entire dataset (all birds, all colonies) to identify likely foraging locations.

\section{Foraging area estimation}

For each colony, in each year and each period of the breeding season, we used likely foraging locations to calculate kernel density maps in ArcGIS over a grid of $1 \mathrm{~km}^{2}$ cells using a bandwidth (h) of $16 \mathrm{~km}$ chosen to produce contiguous cores without oversmoothing (Fig. S4 in the Supplement). We used the $90 \%$ kernel density contours as an estimate of each colony's foraging area in each year and stage of the breeding season. We used the $50 \%$ kernel density contours as a conservative estimate of core foraging areas. We estimated the sharing of foraging areas in each year and breeding stage by calculating the percentage of the area bounded by each colony's $90 \%$ and $50 \%$ occupancy contours (themselves determined in ArcGIS) that overlapped with each other colony's equivalent area.

\section{RESULTS}

\section{Impacts}

The median duration of deployments was $8 \mathrm{~d}$ (interquartile range [IQR] 5-11) during incubation and $5 \mathrm{~d}$ (IQR 3 to 8) during chick rearing. Overall, incubation deployments recorded 1.1 foraging trips, and chick-rearing deployments recorded 2.4 trips. The departure masses of birds for each deployment were lighter during incubation than chick rearing $(405 \pm 31$ $\mathrm{g}$ and $424 \pm 36 \mathrm{~g}$ ) respectively; 2 sample $t$-test $t(258)=$ $3.88, \mathrm{p}<0.001$ ). We found no significant differences in the masses of birds from different colonies in each period (Copeland incubation $407 \pm 27 \mathrm{~g}$, Skomer incubation $402 \pm 37 \mathrm{~g} ; 2$ sample $t$-test $t(69)=0.67, \mathrm{p}=$ 0.505 . Rum rearing $423 \pm 47 \mathrm{~g}$, Copeland rearing $428 \pm 28 \mathrm{~g}$, Skomer rearing $428 \pm 38 \mathrm{~g}$, Lundy rearing $412 \pm 36 \mathrm{~g} ;$ ANOVA $F_{3,181}=2.08, \mathrm{p}=0.104$ ). For 51 nests from which adults were tracked on Skomer during incubation 2009-2011, hatching success was similar $(70.6 \%)$ to that of 120 nests where no incubation tracking had been carried out $(74.2 \%)$. For 39 nests from which adults were tracked on Skomer during chick-rearing 2009-2011, probable fledging success (actual fledging is difficult to assess) was similar $(97.4 \%)$ to that of 70 nests where no tracking had been carried out $(98.6 \%)$. During the tracking periods in 2009 and 2011, the mean growth rate of 24 chicks whose parents carried devices $\left(6.9 \pm 5.2 \mathrm{~g} \mathrm{~d}^{-1}\right)$ was slightly lower than, but not significantly different from, that of 23 chicks in control nests $\left(7.5 \pm 4.5 \mathrm{~g} \mathrm{~d}^{-1}\right.$; 2 -sample $t$-test $t(46)=0.44, \mathrm{p}=0.66)$.

\section{Foraging trips}

We recorded 528 foraging trips during 259 deployments on 169 individuals (Table 1). Most of the tracked foraging trips (94\%) were complete (Copeland incubation $83 \%$, Skomer incubation $77 \%$, Rum chick-rearing 96\%, Copeland chick-rearing 97\%, Skomer chick-rearing $93 \%$ and Lundy chick-rearing $100 \%$ ), and on only 5 trips did the GPS fail before the bird had reached its likely maximum distance from the colony. Foraging trip metrics were calculated for each colony and breeding stage (Table 2) and tracks were plotted individually (see Figs. S6 \& S7 in the Supplement at www.int-res.com/articles/suppl/m538 p239_supp.pdf). Overall, foraging activity from the 4 colonies was largely restricted to continental shelf waters, although 6 very long-range trips were made into the Atlantic beyond the continental shelf edge (Fig. S5 in the Supplement).

\section{Foraging distributions}

During incubation, birds from Copeland foraged closer to their colony than did birds from the much larger colony of Skomer, who frequently travelled 
Table 2. Metrics for trips from each colony in each stage of the breeding season, pooled across years. Colony and approximate colony distance to the Irish Sea Front (ISF); period (chick rearing [Chick-R] or incubation [Incub.]); \% of trips that were short distance $\left(\mathrm{S}_{1}<200 \mathrm{~km}\right) ; \%$ of both short and long $\left(\mathrm{L}_{1}>200 \mathrm{~km}\right)$ distance trips that were to the ISF area; medians (and interquartile ranges) of track lengths, trip maximum distances, trip durations, and daily travel distances. The results of generalized linear mixed models (GLMM) of the relationship between trip maximum distance and trip duration are also given

\begin{tabular}{|c|c|c|c|c|c|c|c|c|c|c|c|c|}
\hline \multirow{2}{*}{$\begin{array}{l}\text { Colony } \\
\text { (distance } \\
\text { to ISF, km) }\end{array}$} & \multirow{2}{*}{ Period } & \multirow{2}{*}{$\begin{array}{l}\text { Short } \\
\text { or long } \\
\text { trip }\end{array}$} & \multirow{2}{*}{$\begin{array}{l}\% \\
\text { short } \\
\text { trips }\end{array}$} & \multirow{2}{*}{$\begin{array}{c}\% \text { trips } \\
\text { to } \\
\text { ISF }\end{array}$} & \multirow{2}{*}{$\begin{array}{c}\text { Track } \\
\text { length } \\
(\mathrm{km})\end{array}$} & \multirow{2}{*}{$\begin{array}{l}\text { Trip } \\
\text { max. dist. } \\
(\mathrm{km})\end{array}$} & \multirow{2}{*}{$\begin{array}{l}\text { Trip } \\
\text { dur. } \\
\text { (d) }\end{array}$} & \multirow{2}{*}{$\begin{array}{c}\text { Daily } \\
\text { dist. } \\
\left(\mathrm{km} \mathrm{d}^{-1}\right)\end{array}$} & \multicolumn{4}{|c|}{ - GLMMs } \\
\hline & & & & & & & & & $\mathrm{n}_{\text {trips }}$ & $\mathrm{n}_{\text {birds }}$ & $t$ & $\mathrm{p}$ \\
\hline $\operatorname{Rum}_{(375)}$ & Chick-R & $\begin{array}{l}\mathrm{S} \\
\mathrm{L}\end{array}$ & 92 & $\begin{array}{c}0 \\
60\end{array}$ & $\begin{array}{c}184 \\
(128-274)\end{array}$ & $\begin{array}{c}35 \\
(29-73)\end{array}$ & $\begin{array}{c}1 \\
(1-1)\end{array}$ & $\begin{array}{c}179 \\
(128-226)\end{array}$ & 75 & 20 & 15.64 & $<0.001$ \\
\hline \multirow[t]{2}{*}{$\begin{array}{l}\text { Copeland } \\
(120)\end{array}$} & Incub. & $\begin{array}{l}\mathrm{S} \\
\mathrm{L}\end{array}$ & 95 & $\begin{array}{l}64 \\
50\end{array}$ & $\begin{array}{c}1031 \\
(408-1552)\end{array}$ & $\begin{array}{c}119 \\
(73-152)\end{array}$ & $\begin{array}{c}7 \\
(5-9)\end{array}$ & $\begin{array}{c}144 \\
(114-172)\end{array}$ & 38 & 25 & 4.61 & $<0.001$ \\
\hline & Chick-R & $\begin{array}{l}\mathrm{S} \\
\mathrm{L}\end{array}$ & 100 & $\begin{array}{c}44 \\
-\end{array}$ & $\begin{array}{c}255 \\
(129-545)\end{array}$ & $\begin{array}{c}56 \\
(27-93)\end{array}$ & $\begin{array}{c}1 \\
(1-3)\end{array}$ & $\begin{array}{c}169 \\
(121-206)\end{array}$ & 157 & 45 & 13.6 & $<0.001$ \\
\hline \multirow[t]{2}{*}{$\begin{array}{l}\text { Skomer } \\
(215)\end{array}$} & Incub. & $\begin{array}{l}\mathrm{S} \\
\mathrm{L}\end{array}$ & 35 & $\begin{array}{c}0 \\
73\end{array}$ & $\begin{array}{c}1517 \\
(925-2117)\end{array}$ & $\begin{array}{c}254 \\
(176-295)\end{array}$ & $\begin{array}{c}8 \\
(7-11)\end{array}$ & $\begin{array}{c}180 \\
(165-219)\end{array}$ & 23 & 20 & 3.76 & 0.064 \\
\hline & Chick-R & $\begin{array}{l}\mathrm{S} \\
\mathrm{L}\end{array}$ & 85 & $\begin{array}{c}0 \\
100\end{array}$ & $\begin{array}{c}297 \\
(203-581)\end{array}$ & $\begin{array}{c}86 \\
(61-134)\end{array}$ & $\begin{array}{c}1 \\
(1-2)\end{array}$ & $\begin{array}{c}223 \\
(186-259)\end{array}$ & 131 & 53 & 21.28 & $<0.001$ \\
\hline $\begin{array}{r}\text { Lundy } \\
(280)\end{array}$ & Chick-R & $\begin{array}{l}\mathrm{S} \\
\mathrm{L}\end{array}$ & 82 & $\begin{array}{c}0 \\
83\end{array}$ & $\begin{array}{c}305 \\
(169-592)\end{array}$ & $\begin{array}{c}49 \\
(29-104)\end{array}$ & $\begin{array}{c}2 \\
(1-3)\end{array}$ & $\begin{array}{c}181 \\
(152-225)\end{array}$ & 73 & 24 & 7.88 & $<0.001$ \\
\hline
\end{tabular}

north to forage in areas of the Irish Sea that were also being used by birds from Copeland, particularly in 2010 and 2011 (Fig. 1a-c, see Fig. S6 in the Supplement). This led to a variable but sometimes high degree of overlap ( 7 to $69 \%$ of Copeland's $90 \%$ foraging area and 2 to $64 \%$ of Skomer's) between the 2 colonies in different years close to the Irish Sea Front (ISF) and Western Irish Sea (WIS) (Simpson \& Hunter 1974) (Fig. 1). The overlap between the $50 \%$ core foraging areas was smaller across years (0 to $18 \%$ of Copeland's $50 \%$ foraging area and 0 to $13 \%$ of Skomer's).

During chick rearing, local foraging was seen close to all 4 respective colonies (Fig. $1 \mathrm{~d}-\mathrm{f}$, see Fig. $\mathrm{S} 7$ in the Supplement). The only local foraging areas that overlapped were those of Skomer and Lundy $(75 \mathrm{~km}$ apart), where there was an area of overlap approximately equidistant from both colonies in 2009 and $2010(7-10 \%$ of Skomer's $90 \%$ foraging area and $13-28 \%$ of Lundy's foraging area; Fig. 1). However, no local overlap was seen between the $50 \%$ core areas of Skomer and Lundy.

In addition (during chick rearing), the foraging areas of birds from the 4 colonies also often overlapped in one important region, around the ISF and WIS. Ninety per cent foraging areas overlapped spatially in this region for up to 4 colonies and overlapped both spatially and temporally for up to 3 colonies (Fig. 1). Overlap in this region with the 3 other colonies varied between $0-31 \%$ of Rum's $90 \%$ foraging area, $4-60 \%$ of Copeland's foraging area,
$0-21 \%$ of Skomer's foraging area, and $0-34 \%$ of Lundy's foraging area. Only in 2010 was there substantial overlap between the $50 \%$ core areas calculated for the birds tracked in this study, comprising, in comparison to the 3 other colonies, $3-6 \%$ of Rum's foraging area, $2-6 \%$ of Copeland's foraging area, $1-2 \%$ of Skomer's foraging area, and $2-3 \%$ of Lundy's foraging area.

\section{Trip distance and duration in relation to the shared foraging area}

During incubation and chick-rearing, trip duration increased with trip maximum distance $(p<0.001)$ except perhaps for incubation trips from Skomer $(\mathrm{p}=$ 0.064) (Table 2). During incubation, most trips from Copeland $(95 \%)$ were $<200 \mathrm{~km}$ maximum distance, and of these, $64 \%$ visited the ISF/WIS (Table 2). Most incubation trips from Skomer $(65 \%)$ were $>200 \mathrm{~km}$ maximum distance, and $73 \%$ of these visited the ISF/WIS (Table 2). During chick-rearing, the majority of trips from all 4 colonies were relatively local $(<200 \mathrm{~km})$, but birds from Rum, Skomer, and Lundy also made less frequent long-distance trips. All longdistance trips from Skomer and most from Rum $(60 \%)$ and Lundy $(83 \%)$ visited the ISF/WIS area (Table 2). The percentage of trips visiting the ISF/WIS decreased monotonically with distance of the colony from the approximate position of the ISF: $5 \%$ from Rum ( $375 \mathrm{~km}$ from ISF), $7 \%$ from Lundy 

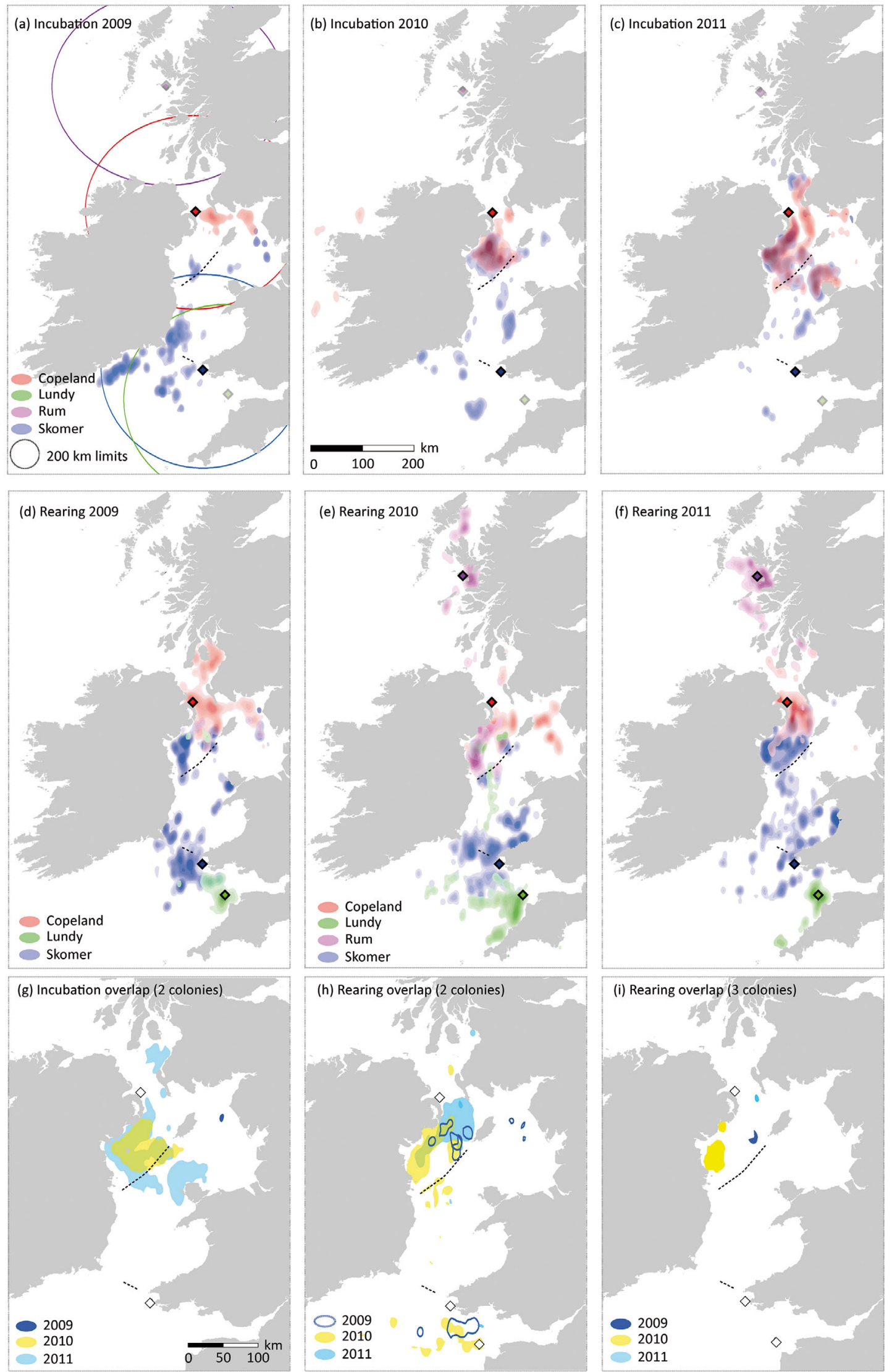
( $280 \mathrm{~km}$ from ISF), $15 \%$ from Skomer $(\sim 215 \mathrm{~km}$ from ISF), and $44 \%$ from Copeland $(\sim 120 \mathrm{~km}$ from ISF).

\section{DISCUSSION}

Foraging activity in breeding shearwaters was derived from GPS data, filtered and validated using additional diving data, collected from 169 individual birds at 4 different colonies, often simultaneously. This allowed us, at least within the limits of the study locations and period, to determine the likely spatial and temporal extent of foraging, and crucially the overlap, among birds from different colonies.

Our data show that during incubation, birds from Copeland made relatively local trips $(<200 \mathrm{~km}$ from the colony), the majority to the ISF/WIS. Birds from Skomer also made local trips, but most trips extended further from the colony $(>200 \mathrm{~km})$ and most of those were also to the ISF/WIS. In general, most longerduration trips ( $>6 \mathrm{~d}$ ) from either colony tended to visit this area. During incubation, at least in 2 of the years studied (2010 and 2011), there was thus striking temporal and spatial overlap in the foraging activity of birds from Copeland and Skomer, considering their geographic separation. Reliable aggregations of prey may be limited during the early breeding season, but because the waters associated with the tidal front system around the ISF become stratified between April and June (depending on the weather), supporting high marine productivity (Stone et al. 1994), even in early summer this area may provide a valuable resource for off-duty incubating birds to recover body condition.

Later in the summer during chick-rearing, the foraging distributions of tracked birds suggested a mixed pattern combining segregation and sharing at different scales, with weak support for colony segregation during local foraging trips, but strong evidence for overlap during longer excursions. Birds from all 4 colonies foraged in relatively local areas $(<200 \mathrm{~km})$ as expected for a central place forager constrained to return frequently to provision a chick: there was only limited overlap between the local foraging distributions of Skomer and Lundy, which are only $75 \mathrm{~km}$ apart. But in addition to these frequent local trips, birds from Rum, Skomer, and Lundy also made less-frequent longer foraging trips (in both distance and duration), and these were mostly to the ISF/WIS area. Copeland birds also made frequent local foraging trips here. As a result, there was striking spatial and temporal foraging overlap from up to 4 colonies within this restricted (highly productive: see below) area of the Irish Sea. Spatial and temporal overlap here was even evident between the highly conservative $50 \%$ foraging core areas. These findings are consistent with being driven by a dual foraging strategy, which mixes short and long foraging excursions and has been found in this (Gray \& Hamer 2001, Shoji et al. 2015) and other (though not all: Phillips et al. 2009) procellariiform species (Chaurand \& Weimerskirch 1994, Weimerskirch et al. 1994, 1997, Weimerskirch 1998, Magalhães et al. 2008). Dual foraging behaviour may allow parents to regulate reproductive effort by combining short trips to local areas (which are hypothesized to maximise food delivery rate to the chick at a net energetic cost to parents) with less frequent, longer trips to more distant productive areas (hypothesized to facilitate recovery of parent body condition). The significant relationship between maximum trip distance and trip duration, though not surprising, is also consistent with the hypothesis that one function of longer duration trips is to accommodate travel to more distant resources rather than simply to allow periods of selffueling, which might also be done locally. In the present study, the majority of longer trips from several widely separated colonies visited the ISF/WIS, so this single foraging area may have an important functional role in sustaining parental condition across the species' core breeding range and even when birds are provisioning chicks (Shoji et al. 2015).

Given that we have tracked only very small fractions of the populations breeding at each colony, our data suggest potentially high levels of interaction between different colonies at the shared foraging area, despite its remoteness from some colonies. We

Fig. 1. (a-f) Foraging density maps calculated for incubation and chick-rearing in each year. Kernel densities were calculated using those locations classified as foraging by the filtering process. Distributions for each colony: Rum (purple), Copeland (red), Skomer (blue) and Lundy (green) are shaded from low density (lightest colour) to high density (darkest colour) and are translucent to show overlap between colonies. The approximate positions of the Irish Sea Front (curved dotted line) and Celtic Sea Front (dotted straight line) are shown. The colonies are shown by a diamond of the same colour as the kernels, and $200 \mathrm{~km}$ limits (threshold between short and long trips) around each colony are shown on panel (a), matching the colour of their origin colony. ( $g-\mathrm{i})$ Size and extent of overlap between foraging ranges (90\% occupancy kernels) between $(g, h) 2$ colonies during incubation and chick-rearing or (i) 3 colonies during chick-rearing each year in 2009 (dark blue), 2010 (yellow) and 2011 (light blue). Colonies are indicated by black diamonds, and frontal systems as in (a-f) 
predict that birds from other untracked colonies will also forage here regularly. However, since the frequency of recorded visits to this area declined monotonically with increasing distance from the colony, any advantage to foraging at the ISF/WIS probably is significantly affected by the energetic costs of travelling there. Tracking the movements of birds from more distant colonies (e.g. St Kilda, $\sim 500 \mathrm{~km}$ northwest, the Scilly Isles, $450 \mathrm{~km}$ south, or colonies off the west coast of Ireland, separated by a major landmass; see Fig. S1 in the Supplement) might reveal the spatial limits at which this trade-off becomes uneconomic, or whether there are perhaps additional, as yet undiscovered, shared foraging areas in the Atlantic.

Intraspecific competition at foraging grounds is likely to increase as a function of conspecific density and may be significant enough to cause prey depletion, limit colony size and foraging ranges, and select for differential foraging strategies between sexes (Ashmole 1963, Furness \& Birkhead 1984, Birt et al. 1987, Cairns 1989, Lewis et al. 2001, Grémillet et al. 2004, Wakefield et al. 2011, 2013). Although not strong evidence, the relative segregation of local foraging distributions for birds from Skomer and Lundy is consistent with the hypothesis that intraspecific inter-colony competition for foraging resources is important in shaping foraging distributions. An effect of intra-colony competition is also consistent with the finding that foraging trips from the largest colony (Skomer) tended to extend furthest from the colony, but this relationship was not consistent across the remaining smaller colonies.

The sharing of a foraging area during longer range foraging trips, however, suggests that intraspecific competition does not always control the spatial distribution of foraging and is evidence that competitive segregation and resource sharing might co-drive atsea distributions in seabirds with dual foraging strategies. It seems plausible that heightened productivity of an isolated but predictable location could free birds from effective competition and promote sharing, whilst density-dependent competition remains important at less productive locations that are closer to major colonies. The aggregation of foraging seabirds at frontal systems, including the ISF, is well documented (Le Fèvre 1986, Stone et al. 1994, Schneider 1990, Begg \& Reid 1997, Durazo et al. 1998, Vlietstra et al. 2005). Frontal systems increase primary production (Savidge 1976, Beardall et al. 1982, Le Fèvre 1986, Yoder et al. 1994) and encourage aggregation (Scrope-Howe \& Jones 1985) or physical retention of zooplankton and nektonic organisms (Herman et al. 1981, Yoder et al. 1994), attracting high densities of pelagic fish (Laurs et al. 1977, Alemany et al. 2009). Physical retention of coastally spawned fish larvae by associated cyclonic gyre currents (as in the WIS) can also drive stable seasonal recruitment (Hill et al. 1994, Dickey-Collas et al. 1997), providing a reliable prey resource for higher trophic levels, including seabirds (Durazo et al. 1998).

Finally, generalizing from movement data collected on animals carrying devices must always be done with the caveat that natural behaviour may be altered, and early telemetry studies in procellariiforms have collectively shown negative impacts (Sæther et al. 1993, Phillips et al. 2003). Our shortterm deployments utilising tape (not harness) attachments caused no immediate desertions and, when comparing experimental nests with controls, produced no significant effects on medium-term (breeding season) reproductive success or on provisioning (although there was a small difference in mean meal payload delivery). Small, unmeasured effects on atsea behaviour and trip duration are still possible, but since device and body masses were similar across colonies, inter-colony comparisons of behaviour should remain unbiased.

\section{CONCLUSIONS}

The shared use of a restricted foraging area by breeding birds from colonies across the Manx shearwater's core breeding range may have important ecological implications. First, it indicates that both competitive segregation (locally) and resource sharing (more remotely) may co-drive the pattern of seabird distribution at sea, at least in species exhibiting a dual foraging strategy. Second, it suggests that the breeding success and adult survival at diverse colonies across a large geographical range and encompassing the majority of the species' breeding population may be functionally dependent on a single resource, even though this may not be obvious from the general pattern of at-sea distributions where the provenance of individuals is unknown. Thus, threat to a single resource area (for example from overfishing, pollution, habitat degradation, or perhaps renewable-energy developments) could impact upon the majority of the breeding population, even though birds are known to forage in many other places. In addition, the area is likely to be of importance to nonbreeders (immature, divorced, widowed or failed breeding) that are less tied to colonies and may con- 
stitute as much as half of the population. Finally, we hypothesise that such a shared resource might also act as a centre for information transfer (about where other colonies are located) that could in turn affect population structure and recruitment.

Acknowledgements. We thank the Skomer and Skokholm Islands Advisory Committee, Copeland Bird Observatory, Scottish Natural Heritage, the Landmark Trust, and the National Trust for Scotland for permission to conduct the project on each of the Islands. We also thank the island staff and volunteers, especially J. and D. Millborrow, C. Taylor, D. Boyle, N. McKee, G. Henderson, N. Saunders, H. Brooker, T. Jones, T. Davis, A. Douse, L. Watt, A. Ramsey, C. Laurie, M. Carty, J. Craig, F. Knowles, and many others. R. Mavor and T. Dunn (JNCC) helpfully provided data on colony size estimates from Seabird 2000. This work was funded by Microsoft Research, Cambridge, the UK Natural Environment Research Council, the Northern Ireland Environment Agency, Scottish Natural Heritage, the Royal Society for the Protection of Birds, the Birds of Lundy Fund, and Merton College, Oxford.

\section{LITERATURE CITED}

Alemany D, Acha EM, Iribarne O (2009) The relationship between marine fronts and fish diversity in the Patagonian Shelf Large Marine Ecosystem. J Biogeogr 36: 2111-2124

> Ashmole NP (1963) The regulation of numbers of tropical oceanic birds. Ibis 103b:458-473

> Beardall J, Foster P, Voltolina D, Savidge G (1982) Observations on the surface water characteristics in the western Irish Sea: July 1977. Estuar Coast Shelf Sci 14:589-598

Begg GS, Reid JB (1997) Spatial variation in seabird density at a shallow sea tidal mixing front in the Irish Sea. ICES J Mar Sci 54:552-565

> Birt VL, Birt TP, Goulet D, Cairns DK, Montevecchi WA (1987) Ashmole's halo: direct evidence for prey depletion by a seabird. Mar Ecol Prog Ser 40:205-208

Bograd SJ, Block BA, Costa DP, Godley BJ (2010) Biologging technologies: new tools for conservation. Introduction. Endang Species Res 10:1-7

Brooke M (1990) The Manx shearwater. T \& AD Poyser, London

Burger AE, Shaffer SA (2008) Perspectives in ornithology: application of tracking and data-logging technology in research and conservation of seabirds. Auk 125:253-264

Cairns DK (1989) The regulation of seabird colony size: a hinterland model. Am Nat 134:141-146

Ceia FR, Paiva VH, Ceia RS, Hervías S, Garthe S, Marques JC, Ramos JA (2015) Spatial foraging segregation by close neighbours in a wide-ranging seabird. Oecologia 177:431-440

Chaurand T, Weimerskirch H (1994) The regular alternation of short and long foraging trips in the blue petrel Halobaena caerulea: a previously undescribed strategy of food provisioning in a pelagic seabird. J Anim Ecol 63: 275-282

> Dean B, Freeman R, Kirk H, Leonard K, Phillips RA, Perrins CM, Guilford T (2012) Behavioural mapping of a pelagic seabird: combining multiple sensors and a hidden Mar- kov model reveals the distribution of at-sea behaviour. J R Soc Interface 10:20120570, doi:10.1098/rsif.2012.0570

Dickey-Collas M, Brown J, Fernand L, Hill AE, Horsburgh KJ, Garvine RW (1997) Does the western Irish Sea gyre influence the distribution of pelagic juvenile fish? J Fish Biol 51:206-229

> Durazo R, Harrison NM, Hill AE (1998) Seabird observations at a tidal mixing front in the Irish Sea. Estuar Coast Shelf Sci 47:153-164

- Einoder LD (2009) A review of the use of seabirds as indicators in fisheries and ecosystem management. Fish Res 95: 6-13

- Fauchald P (2009) Spatial interaction between seabirds and prey: review and synthesis. Mar Ecol Prog Ser 391: 139-151

Finney SK, Wanless S, Harris MP (1999) The effect of weather conditions on the feeding behaviour of a diving bird, the common guillemot Uria aalge. J Avian Biol 30: 23-30

- Freeman R, Dean B, Kirk H, Leonard K, Phillips RA, Perrins CM, Guilford T (2013) Predictive ethoinformatics reveals the complex migratory behaviour of a pelagic seabird. J R Soc Interface 10:20130279

Furness RW, Birkhead TR (1984) Seabird colony distributions suggest competition for food supplies during the breeding season. Nature 311:655-656

> Garthe S, Markones N, Hüppop O, Adler S (2009) Effects of hydrographic and meteorological factors on seasonal seabird abundance in the southern North Sea. Mar Ecol Prog Ser 391:243-255

González-Solís J, Shaffer SA (2009) Introduction and synthesis: spatial ecology of seabirds at sea. Mar Ecol Prog Ser 391:117-120

Granadeiro JP, Phillips RA, Brickle P, Catry P (2011) Albatrosses following fishing vessels: How badly hooked are they on an easy meal? PLoS ONE 6:e17467

> Gray CM, Hamer KC (2001) Food provisioning behaviour of male and female Manx Shearwaters, Puffinus puffinus. Anim Behav 62:117-121

> Grémillet D, Boulinier T (2009) Spatial ecology and conservation of seabirds facing global climate change: a review. Mar Ecol Prog Ser 391:121-137

> Grémillet D, Dell'Omo G, Ryan PG, Peters G, RopertCoudert Y, Weeks SJ (2004) Offshore diplomacy, or how seabirds mitigate intra-specific competition: a case study based on GPS tracking of Cape gannets from neighbouring colonies. Mar Ecol Prog Ser 268:265-279

Guilford TC, Meade J, Freeman R, Biro D and others (2008) GPS tracking of the foraging movements of Manx Shearwaters Puffinus puffinus breeding on Skomer Island, Wales. Ibis 150:462-473

Guilford T, Wynn R, McMinn M, Rodriguez A and others (2012) Geolocators reveal migration and pre-breeding behaviour of the critically endangered Balearic shearwater Puffinus mauretanicus. PLoS ONE 7:e33753

Halpern BS, Walbridge S, Selkoe KA, Kappel CV and others (2008) A global map of human impact on marine ecosystems. Science 319:948-952

- Hamer KC, Humphreys EM, Magalhães MC, Garthe S and others (2009) Fine-scale foraging behaviour of a medium-ranging marine predator. J Anim Ecol 78:880-889

Herman AW, Sameoto DD, Longhurst AR (1981) Vertical and horizontal distribution patterns of copepods near the shelf break south of Nova Scotia. Can J Fish Aquat Sci 38:1065-1076 
Hill AE, Durazo R, Smeed DD (1994) Observations of a cyclonic gyre in the western Irish Sea. Cont Shelf Res 14: 479-490

Laurs RM, Yuen HSH, Johnson JH (1977) Small-scale movements of albacore, Thunnus alalunga, in relation to ocean features as indicated by ultrasonic tracking and oceanographic sampling. Fish Bull US 75:347-355

> Le Fèvre J (1986) Aspects of the biology of frontal systems. Adv Mar Biol 23:163-299

> Lewis S, Sherratt TN, Hamer KC, Wanless S (2001) Evidence of intra-specific competition for food in a pelagic seabird. Nature 412:816-819

> Lewison R, Oro D, Godley B, Underhill L and others (2012) Research priorities for seabirds: improving conservation and management in the 21st century. Endang Species Res 17:93-121

Magalhães MC, Santos RS, Hamer KC (2008) Dual-foraging of Cory's shearwaters in the Azores: feeding locations, behaviour at sea and implications for food provisioning of chicks. Mar Ecol Prog Ser 359:283-293

Mitchell PI, Newton SF, Ratcliffe N, Dunn TE (2004) Seabird populations of Britain and Ireland, results of the Seabird 2000 census (1998-2002). T \& AD Poyser, London

Paiva VH, Geraldes P, Ramírez I, Garthe S, Ramos JA (2010) How area restricted search of a pelagic seabird changes while performing a dual foraging strategy. Oikos 119: 1423-1434

> Phillips RA, Xavier JC, Croxall JP (2003) Effects of satellite transmitters on albatrosses and petrels. Auk 120: 1082-1090

Phillips RA, Croxall JP, Silk JRD, Briggs DR (2007) Foraging ecology of albatrosses and petrels from South Georgia: two decades of insights from tracking technologies. Aquat Conserv 17:S6-S21

Phillips RA, Wakefield ED, Croxall JP, Fukuda A, Higuchi H (2009) Albatross foraging behaviour: no evidence for dual foraging, and limited support for anticipatory regulation of provisioning at South Georgia. Mar Ecol Prog Ser 391:279-292

Pinaud D, Weimerskirch H (2007) At-sea distribution and scale-dependent foraging behaviour of petrels and albatrosses: a comparative study. J Anim Ecol 76:9-19

Ramos P, Granadeiro JP, Rodriguez B, Navarro J and others (2013) Meta-populationn feeding grounds of Cory's shearwater in the subtropical Atlantic Ocean: implications for definition of Marine Protected Areas based on tracking studies. Divers Distrib 19:1284-1298

Ricklefs RE (1990) Seabird life histories and the marine environment: some speculations. Colon Waterbirds 13:1-6

> Riou S, Hamer KC (2008) Predation risk and reproductive effort: impacts of moonlight on food provisioning and chick growth in Manx shearwaters. Anim Behav 76: 1743-1748

Rutz C, Hays GC (2009) New frontiers in biologging science. Biol Lett 5:289-292

> Sæther B, Andersen R, Pedersen HC (1993) Regulation of parental effort in a long-lived seabird: an experimental manipulation of the cost of reproduction in the Antarctic Petrel, Thalassoica antarctica. Behav Ecol Sociobiol 33: $147-150$

Savidge G (1976) A preliminary study of the distribution of chlorophyll $a$ in the vicinity of fronts in the Celtic and western Irish Seas. Estuar Coast Mar Sci 4:617-625

Schneider DD (1990) Seabirds and fronts: a brief overview. Polar Res 8:17-22

Scrope-Howe S, Jones DA (1985) Biological studies in the vicinity of a shallow-sea tidal mixing front V. Composition, abundance and distribution of zooplankton in the western Irish Sea, April 1980 to November 1981. Philos Trans R Soc Lond B 310:501-519

> Shoji A, Aris-Brosou S, Fayet A, Padget O, Perrins CM, Guilford $T$ (2015) Dual foraging and pair coordination during chick provisioning by Manx shearwaters: empirical evidence supported by a simple model. J Exp Biol 218: 2116-2123

Simpson JH, Hunter JR (1974) Fronts in the Irish Sea. Nature 250:404-406

Stone CJ, Webb A, Tasker ML (1994) The distribution of Manx shearwaters Puffinus puffinus in north-west European waters. Bird Study 41:170-180

Torres LG, Sagar PM, Thompson DR, Phillips RA (2013) Scaling-down the analysis of seabird-fishery interactions. Mar Ecol Prog Ser 473:275-289

> Vlietstra LS, Coyle KO, Kachel NB, Hunt GL Jr (2005) Tidal front affects the size of prey used by a top marine predator, the short-tailed shearwater (Puffinus tenuirostris). Fish Oceanogr 14:196-211

Votier SC, Bearhop S, Witt MJ, Inger R, Thompson DR, Newton J (2010) Individual responses of seabirds to commercial fisheries revealed using GPS tracking, stable isotopes and vessel monitoring systems. J Appl Ecol 47: 487-497

Wakefield ED, Phillips RA, Trathan PN, Arata J and others (2011) Habitat preference, accessibility, and competition limit the global distribution of breeding black-browed albatrosses. Ecol Monogr 81:141-167

Wakefield ED, Bodey TW, Bearhop S, Blackburn J and others (2013) Space partitioning without territoriality in gannets. Science 341:68-70

> Weimerskirch H (1998) How can a pelagic seabird provision its chick when relying on a distant food resource? Cyclic attendance at the colony, foraging decision and body condition in sooty shearwaters. J Anim Ecol 67:99-109

- Weimerskirch H, Chastel O, Ackermann L, Chaurand T, Cuenot-Haillet F, Hindermeyer X, Judas J (1994) Alternate long and short foraging trips in pelagic seabird parents. Anim Behav 47:472-476

Weimerskirch H, Cherel Y, Cuenot-Chaillet F Ridoux V (1997) Alternative foraging strategies and resource allocation by male and female wandering albatrosses. Ecology 78:2051-2063

> Weimerskirch H, Pinaud D, Pawlowski F, Bost CA (2007) Does prey capture induce area-restricted search? A finescale study using GPS in a marine predator, the wandering albatross. Am Nat 170:734-743

Wilson RP, Vandenabeele SP (2012) Technological innovation in archival tags used in seabird research. Mar Ecol Prog Ser 451:245-262

Yamamoto T, Takahashi A, Yoda K, Katsumata N, Watanabe S, Sato K, Trathan PN (2008) The lunar cycle affects at-sea behaviour in a pelagic seabird, the streaked shearwater, Calonectris leucomelas. Anim Behav 76:1647-1652

> Yoder JA, Ackleson SG, Barber RT, Flament P, Balch WM (1994) A line in the sea. Nature 371:689-692 